\title{
Article
}

\section{Can the offence behaviours of stranger rapists discriminate between UK and non- UK nationals}

\author{
Almond, Louise, Mcmanus, Michelle Ann and Curtis, Gemma \\ Available at http://clok.uclan.ac.uk/24501/ \\ Almond, Louise, Mcmanus, Michelle Ann ORCID: 0000-0002-0095-1071 and \\ Curtis, Gemma (2019) Can the offence behaviours of stranger rapists \\ discriminate between UK and non-UK nationals. Journal of Aggression, Conflict \\ and Peace Research, 11 (1). pp. 67-76. ISSN 1759-6599
}

It is advisable to refer to the publisher's version if you intend to cite from the work. http://dx.doi.org/10.1108/jacpr-04-2018-0357

For more information about UCLan's research in this area go to http://www.uclan.ac.uk/researchgroups/ and search for <name of research Group>.

For information about Research generally at UCLan please go to http://www.uclan.ac.uk/research/

All outputs in CLoK are protected by Intellectual Property Rights law, including Copyright law. Copyright, IPR and Moral Rights for the works on this site are retained by the individual authors and/or other copyright owners. Terms and conditions for use of this material are defined in the policies page.

\section{CLoK}

Central Lancashire online Knowledge www.clok.uclan.ac.uk

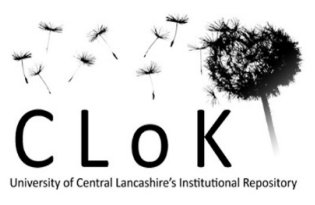


CAN THE OFFENCE BEHAVIOURS OF STRANGER RAPISTS DISCRIMINATE BETWEEN UK AND NON-UK NATIONALS?

Dr Louise Almond ${ }^{1}$, Dr Michelle McManus² \& Gemma Curtis ${ }^{1}$

UUniversity of Liverpool

School of Psychology

2University of Central Lancashire

Forensic and Applied Sciences 


\section{Introduction}

Due to the increasing prevalence of rape, the number of people it affects and the heterogeneity of offenders, rape is widely researched in the forensic field. Since 2014, the reported number of sexual offences has risen by $41 \%$ (Office for National Statistics, 2015) with around $16 \%$ of serious sexual assaults committed by a stranger in $2013 / 14$. Stranger rapes are difficult to solve due to a multitude of factors, including: investigators working under time pressures, limited resources (Hakkanen, Lindlof \& Santtila, 2004), a lack of physical evidence to help generate investigative inferences and a reliance on victim accounts (Corovic, Christianson \& Bergman, 2012). Forensic research has, therefore, increasingly focused on generating inferences between crime-scene behaviours and characteristics of the offender to aid this difficult investigative process (Mokros \& Alison, 2002).

Offender Profiles and Behavioural Investigative Advisors

The 'A to $C$ equation' is the core component of offender profiling (Canter, 2011), whereby crime-scene actions $(A)$ are used to generate inferences about an unknown offender's background characteristics $(C)$. This equation is based upon the assumption of homology, which states that offenders who offend in similar ways and display similar offence behaviours will also share similar background characteristics (Petherick \& Ferguson, 2012). Historically, there has been scepticism within the Police and criminal justice practitioners around the utility of offender profiling and its apparent lack of validity (Alison et al, 2010). As a result of the increasing scientific scrutiny within the discipline, the UK uses Behavioural Investigative Advisors (BIA's) who develop reliable and valid offender profiles. They use evidence-based methods by focusing on the overt behaviours at a crime-scene (Alison, McLean \& Almond, 2007). 
All BIA's must specify their reasoning and provide theoretical and/or empirical evidence for each inference made between crime-scene behaviours and offender characteristics (Alison, Smith, Eastman \& Rainbow, 2003), as any advice based on unreliable research can potentially cause negative consequences within the investigation (Lundrigan \& Müller-Johnson, 2013). This can be done by either conducting bivariate associations between individual behaviours and characteristics, or using thematic approaches that cluster individual offence behaviours into themes (Corovic, 2013). Research has found that bi-variate associations can identify offender characteristics significantly better than thematic approaches (Goodwill, Alison \& Beech, 2009).

\section{Offenders with non-UK vs. UK Nationalities}

In UK prisons, around $14 \%$ of the prison population are born outside of the UK: Just under 10,000 non-UK nationals were documented at the end of March 2016 from 166 different countries, over half from nine countries (Dempsey, 2016). The Ministry of Justice (2010) report that $34 \%$ of crimes committed by the non-UK prison population are either violent offences $(22 \%)$ or sexual offences (12\%), representing a $10 \%$ and $9 \%$ rise respectively, compared to the previous year. This is paired with an increased anxiety within the UK relating to immigration and crime, with public opinion holding that non-UK offenders are more dangerous than their UK counterparts (Banks, 2011). Assessing whether offences committed by non-UK nationals are becoming more frequent and serious is impeded by the scarcity of data provided by the Ministry of Justice (Banks, 2011).

Consequently, there has been a marked growth in forensic research surrounding the non-UK national prison population in the UK. The data suggests that although the size of this population is increasing, there is little evidence to support the notion that 
non-UK offenders are more dangerous (Banks, 2011). A major problem that research faces is the lack of a distinction made between UK national and non-UK offenders within forensic samples. This distinction is important for the development of a research base specifically for non-UK offenders, whose criminal histories may only be recorded in their native countries and thus inaccessible for UK Police agencies.

Non-UK offenders are likely to bring to their crimes a wide range of cultural, lingual and religious diversity that may otherwise be absent from crimes committed by UK offenders (Ministry of Justice, 2017). This may potentially result in non-UK offenders presenting different crime-scene behaviours to their UK counterparts.

Possible explanations for why differences may exist within crime scene behaviours between offenders from different nations when committing the same crimes may include: lack of understanding of the UK legal system, variations in how the Police investigate crimes and what constitutes an offence, as different nations have different laws, systems and processes. Relatedly, language barriers between a non-UK offender and a UK victim may result in differences in verbal offence behaviours, specifically the amount and content of speech. Another potential explanation for differences could be personality; McCrae and Terracciano, (2005) found that personality features such as Neuroticism and Narcissism consistently vary between nations.

Using crime-scene information to make predictions about offender characteristics has been shown to aid in resource allocation, narrowing down of nominal searches and identification. However, currently no research exists to understand potential distinctions between UK and non-UK national offenders using their crime scene behaviours. Previous evidence has reliably linked certain crime scene behaviours to specific previous offence histories, with this often used as the first stage of suspect 
prioritisation. As this suspect-narrowing method utilises the Police National Computer, this would only identify those suspects that hold a UK nationality. Indication of a non-UK offender would require additional consideration of international agencies and/or Police forces from other countries in assisting with suspect identification.

\section{Previous Research}

Research investigating bi-variate associations between offence behaviour and offender characteristics indicates that it is possible to obtain an indication of rapists' characteristics from their offence behaviour, specifically regarding their criminal antecedents (Davies, Wittebrood \& Jackson, 1997). Davies and colleagues generated several models to predict, from the rapists' offence behaviours, the probability that an unknown offender would have a particular pre-conviction. The most promising models were those predicting whether the rapist had pre-convictions for burglary, violent offences and whether the offence was a singular occurrence rather than as part of a serial pattern.

A recent replication of Davies and colleagues work was conducted by Almond et al. (2018) using a larger contemporary sample of UK stranger rapists. Their study showed significant differences to Davies and colleagues original data set, regarding both the offence behaviours and the offenders' pre-convictions. Except for drug offences, their contemporary sample was less likely to have any of the pre-conviction offence types and was less likely to use violence, sighting precautions or fingerprint precautions. Criminal behaviour and offender characteristics have, therefore, significantly changed since the 1990s (National Crime Agency, 2015), demonstrating 
the need for contemporary offender research to allow BIA's to draw valid and reliable inferences for investigative utility.

\section{Purpose of This Research}

To date, no research is available to BIA's to provide justifications to infer from the crime-scene that an offender is a UK or Non-UK based on their stranger rape crime scenes. Previous studies (Almond et al., 2018) have highlighted that key offence behaviours were able to predict likely offender history, thus narrowing potential suspect pools for investigative use (BIAs). However, this is not possible to do if the individual is a non-UK citizen, as this information is not easily available to the police. Therefore, the findings of this study may assist in identifying cases where the usual investigative strategy of checking Police National Computer may not be as relevant.

\section{Method}

\section{Sample}

The data was obtained from the SCAS UK database. The dataset used for this research consisted of 651 male stranger rape offences committed against female victims 16 years or over. All the offences occurred post $1^{\text {st }}$ January 2000 . All offences included a single offender and a single victim.

For this research, the term 'stranger rape' was defined as a rape where the offender and victim were unknown to each other. The dataset was split into two samples. The first sample consisted of 217 convicted offenders with a non-UK nationality as recorded on the Police National Computer. There were 65 Nationalities recorded, the most common were Nigeria $(n=16,7.4 \%)$ and Poland $(n=15,6.9 \%)$. Nationality indicates an individual's country of origin, whereas ethnicity refers to their 
racial ancestry. The second sample consisted of 434 convicted offenders with a UK nationality matched for offender age (UK $M=27.73, S D=7.33$; Non-UK $M=28.26$, $\mathrm{SD}=8.98)$. Non-UK nationals committed stranger rapes on significantly younger victims $(M=27.73, S D=7.33)$ compared to $U K$ stranger rapists $(M=30.40, S D=$ 8.98) $(\mathrm{t}(649)=2.503, \mathrm{p}=.013)$

\section{Procedure}

The data extracted from the SCAS database consisted of dichotomous variables, where 1 indicates the presence of a behaviour and 0 indicates an absence. Using a dichotomous approach to analyse data that was not originally intended for research has been shown to elicit more reliability and clarity of results (Almond, McManus, Giles \& Houston, 2015). Offence behaviour consisted of 70 variables (see Table 1), including those used by Almond et al (2018) and extended to include those relating to interpersonal involvement (i.e. self-disclosure; implies prolonged relationship; victim enjoyment reference) and type of violence involved (i.e. minimal, moderate, severe).

\section{Statistical Analysis}

The aim of this study is to predict an outcome variable (UK or non-UK national) based on offence behaviour. Stage One consisted of conducting chi-square analyses to determine whether there were any significant associations between the offence behaviour variables and offender nationality (UK or non-UK national). Due to multiple testing, false-positive significant results needed to be limited. This was achieved by applying Bonferroni corrections to the critical $p$ value. For any significant associations, the odds ratios were calculated to indicate the statistical probability of an offender having a UK or non-UK nationality based on particular offence 
behaviours. Following the boundaries that were proposed by Chen, Cohen and Chen (2010), odds ratios were considered small $(<1.5)$, medium $(1.5-5)$ or large $(>5)$.

Stage 2 consisted of entering any significant offence behaviours (using the critical value of $p<.05$ ) identified by the chi-square analyses into a logistic regression analysis to ensure that the offence variables produced the optimal predictive model for offender nationality. Logistic regression generates a mathematical function that relates the presence or absence of specific offence behaviours to the odds of an offender having a specific characteristic (Aitken, Connolly, Gammerman, Zhang \& Oldfield, 1995). The resulting models assess the predictive ability of numerous independent variables (i.e. offence behaviours) on a categorical dependent variable (i.e. UK or Non-UK offender) (Pallant, 2013).

\section{Results}

Exploring stranger rapists' behaviours and offender nationality (UK or non-UK)

Chi-square analyses were conducted to determine whether there were any significant associations between stranger rape offence behaviours and offender nationality (UK or Non-UK national). Results are only shown for those results that met the critical value of $p<.05$, and those that met the adjusted critical value due to multiple testing (Bonferroni correction, $p<.0007$ ).

\section{Confidence approach}

Within the 651 stranger rapists 323 were recorded as using a confidence approach within the stranger rape (49.6\%). This approach involves the offender attempting to gain the victims trust by starting a conversation or asking them questions, before attacking them. There was a significant association between the offender's method of approach and nationality, $\chi^{2}(1)=5.69, p=.017$. If a stranger rapist used a 
confidence approach, they were 1.5 times $(95 \% \mathrm{Cl}: 1.07-2.07)$ more likely to have a non-UK nationality than a UK nationality. The results indicated that $56.2 \%(n=122)$ of Non-UK nationals used a confidence approach, compared to $46.3 \%(n=201)$ of UK national stranger rapists.

\section{Darkness}

The majority of stranger rapes were committed during darkness $(n=548,84.2 \%)$. When exploring offender nationality, chi-square analysis indicated that Non-UK nationals were significantly associated with committing stranger rape in darkness, $\chi^{2}$ $(1)=6.66, p=.010, \mathrm{OR}=1.91,95 \% \mathrm{Cl}: 1.16-3.13$. The analysis showed that $89.4 \%$ $(n=194)$ Non-UK stranger rapists committed their offence in darkness compared to $81.6 \%(n=354)$ of UK nationals.

\section{Offender Kisses Victim}

Around half of stranger rapes involved the offender kissing the victim $(n=328$, $50.4 \%)$. When exploring across the offender type, it was Non-UK nationals who were 1.42 times more likely to kiss their victim, $\chi^{2}(1)=4.44, p=.035,95 \% \mathrm{Cl}: 1.02-1.97$, with $56.2 \%$ of Non-UK $(n=122)$ compared to $47.5 \%(n=206)$ of UK nationals.

\section{Victim Performs Sex Acts}

Again, around half of the stranger rape offences involved the victim being forced to perform sex acts on the offender $(n=324,49.8 \%)$. However, UK nationals were found to display this behaviour in $54.4 \%(n=236)$ of cases, compared to $40.6 \%$ $(n=88)$ of Non-UK nationals, $\chi^{2}(1)=11.06, p<.001, \mathrm{OR}=1.75,95 \% \mathrm{Cl}: 1.26-2.43$. 


\section{Request Sex Acts}

Similar to the previous finding, just under half of stranger rapes involved requests for sexual acts ( $n=279,42.9 \%$ ) with this most likely to be within the crime behaviours of UK nationals, $\chi^{2}(1)=4.07, p=.044, \mathrm{OR}=1.41,95 \% \mathrm{Cl}: 1.01-1.97$. UK nationals displayed this behaviour in $45.6 \%$ of stranger rape cases $(n=198)$ compared to $37.3 \%$ of Non-UK nationals $(n=81)$.

\section{Offender Apologises}

A low proportion of stranger rape cases involved the offender apologising $(n=91$, 14\%). However, it was UK nationals that were found to significantly display this behaviour $(16.1 \%, n=70)$ compared to Non-UK nationals $(9.7 \%, n=21)$. The analysis indicated that when the offender apologised this indicated an increased odds ratio of $1.79(95 \% \mathrm{Cl} 1.07-3.01)$ of the stranger rapist being of UK nationality, compared to Non-UK, $\chi^{2}(1)=5.01, p=.025$.

\section{Destroy Forensics}

Only 52 stranger rapes involved the destroying of forensic evidence (8\%). Chi-square analysis indicated a significant association with UK nationals more likely $(9.7 \%, n=$ 42) to employ this behaviour compared to Non-UK nationals $(4.6 \%, n=10), \chi^{2}(1)=$ $5.06, p=.025$. The odds ratio indicated that if this behaviour was displayed, this was 2.22 times more likely to identify a UK national than a Non-UK national $(95 \% \mathrm{Cl}: 1.09$ $-4.51)$.

Block Entry/Exit 
Blocking entry/exit points to prevent the victim from leaving the attack location was utilised in 91 stranger rapes (14\%), with this most likely to be employed by Non-UK nationals, $\chi^{2}(1)=5.37, p=.020, \mathrm{OR}=1.70,95 \% \mathrm{Cl}: 1.08-2.66$. Non-UK nationals used this behaviour in $18.4 \%$ of cases $(n=40)$ compared to $11.8 \%$ of UK nationals $(n=51)$.

\section{Weapon Type-Firearm}

Although a low frequency behaviour across all stranger rapes ( $n=18,2.8 \%)$, chisquare analysis indicated that Non-UK nationals were significantly more likely to possess a firearm weapon during the stranger rape offence, $\chi^{2}(1)=12.60, p<.001$ and remained significant once the Bonferroni correction was applied $(p<.0007)$. This association held the highest odds ratio across all comparisons, demonstrating that the presence of a firearm indicated that the offender was 5.47 times $(95 \% \mathrm{Cl}: 1.92-$ 15.54) more likely to be of non-UK nationality, with this present in $6 \%(n=13)$ NonUK nationality, compared to $1.2 \%$ of UK nationality $(n=5)$.

\section{Violence used: Minimal Damage}

Violence was recorded at three levels: minimal (21.2\%), moderate (16.9\%) and severe $(4.6 \%)$, with minimal recording the highest proportion and also the only significant finding when comparing the offender grouping, $X^{2}(1)=5.01, p=.025$. Results found that Non-UK stranger rapists used violence with minimal damage in over a quarter of rapes $(26.3 \%, n=57)$ compared to $18.7 \%$ of UK national rapists ( $\mathrm{n}$ $=81)$, with the odds ratio indicating a higher likelihood of $1.55(95 \% \mathrm{Cl}: 1.05=2.29)$. 


\section{Vaginal Penetration - Hands/Fist/Digital}

Nearly a third of stranger rapes involved vaginal penetration using hands/ fist/digital $(32.4 \%, n=211)$. Chi-square analysis showed that UK nationals were most likely to use this behaviour within their offence $(35.9 \%, n=156)$ compared to Non-UK nationals $(25.3 \%, \mathrm{n}=55), \chi^{2}(1)=7.42, p=.006, \mathrm{OR}=1.65,95 \% \mathrm{Cl}: 1.15-2.38$.

\section{Logistic Regressions Model}

Chi-square analyses between offender Nationality (UK and Non-UK) and crime scene behaviours identified 11 significant associations when using the standard critical value $(p<.05)$ with only one behaviour (Weapon type - Firearm) meeting the adjusted critical value following the Bonferroni correction (see Table 2). When these 11 significant crime scene behaviors were entered into a binary logistic regression the resulting model was significant, $\chi^{2}(11)=67.73, p<.0001$. Seven stranger rape crime scene behaviours were found to significantly contribute to the model: Darkness $(p=.032)$, Offender Kisses Victim $(p=.003)$, Sex Acts by Victim $(p=.001)$, Blocks Entry/Exit points $(p=.017)$, Weapon - Firearm $(p=.001)$, Violence: minimal force $(p=.012)$ and Vaginal Penetration: Hands $(p=.024)$. The resulting model explained between 9.9\% (Cox \& Snell $\mathrm{R}^{2}$ ) and 13.7\% (Nagelkereke $\mathrm{R}^{2}$ ) of the variance of offender Nationality, and correctly classified $69 \%$ of cases $(91.5 \%$ of UK Nationals and $24 \%$ of Non-UK Nationals).

\section{Discussion}

The overall aim of the study was to determine whether it is possible to predict the nationality of a stranger rapist from their offence behaviour. To meet this aim, 70 
offence behaviour variables were explored in relation to their significant associations with offender grouping (UK or Non-UK stranger rapist) and also their individual predictive validity. The results indicated there were several significant findings. The findings revealed within the current study are new as no other research has investigated the offence behaviours of UK and non-UK national stranger rapists.

Analysis across the 70 variables found that 11 crime scene behaviours distinguished UK and Non-UK stranger rapists. Four variables were unable to predict offender grouping within the logistic regression, with chi-square associations recorded: confidence approach, offender requests sex acts, destroys forensics and offender apologises. The other seven were found to have predictive power. Five crime scene behaviours were able to predict the Non-UK stranger rapist grouping: offence committed in daytime, offender kisses victim, offender blocks entry/exit points, minimal violence and firearm weapon in possession at time of offence. For UK stranger rapists the behaviours victim performs sex act on offender and vaginal penetration with hand/fist/digital were predictive of this grouping.

When exploring the offence behaviours associated and predictive of Non-UK and UK stranger rapists some interesting patterns emerged. Non-UK stranger rapists showed a higher presence of possession of firearm weapons, use of low level violence, kissing the victim and blocking any entry or exit points, which may be suggestive of control and low level aggression. In addition, they were less likely than UK counterparts to apologise to the victim. Previous research reports showing differences in the willingness to apologise, with personality features such as narcissism and entitlement being negatively associated with apologising, and neuroticism and agreeableness being positively associated (Howell, Dopko, Turowski \& Buro, 2011). Such personality features are known to consistently vary between 
nations (e.g. McCrae \& Terracciano, 2005), which may explain the difference between UK and non-UK stranger rapists. Future research would need to explore differences in verbal themes between the two samples, and whether this relates to cultural differences, or purely just language barriers.

Non-UK stranger rapists were also least likely to destroy forensic evidence, with UK stranger rapists most likely to utilise this behaviour. There are various potential explanations for this, such as the use of forensic evidence may not be so widely applied within other countries, so offenders are unaware of the forensic evidence they are leaving behind. In addition, this may represent the lack of contact with UK policing and criminal justice system in regards to the processes and procedures in place for such crimes that require thorough forensic examinations of scenes. The experiences of the Non-UK offender in terms of investigative resources and processes that are available within the UK, compared to other countries may also differ, thus resulting in less attention being paid to potential forensic evidence left behind. This is potentially supported by the increased presence of firearms within Non-UK stranger rapes, which held the largest discriminative power of all variables. This may indicate a lack of understanding regarding the seriousness of firearm possession within the UK and subsequent punishment within the criminal justice system. Alternatively, this could indicate greater access to firearms abroad, especially if an offender is from an area recently/currently besieged by war.

In comparison, UK stranger rapists seemed to display more interpersonal behaviours within their stranger rapes. They were more likely to try and get the victim to perform sexual acts and would request the victim to do so. This behaviour of requesting the victims/getting the victim to perform sexual acts may indicate a desire from the offender to make this seem consensual and interpersonal to them, forcing 
the victim into a reactive participant. This supports other research that has suggested some rapists are seeking to engage in a pseudo intimate-relationship (Canter, Bennell, Alison \& Reddy, 2003). Furthering this interpersonal theme within UK stranger rapists, they were also more likely to apologise to the victim, as in Canter's (1994) Victim as Person style of offending.

\section{Limitations}

Despite the large sample size of the study with a total of 651 cases spanning from 2000 to 2015 , there are several limitations that need to be addressed. The data was extracted from a national database provided by SCAS and therefore can be considered a representative sample of UK stranger rape cases. However, this data only contained detected and convicted cases, and it is known that rape offences are hugely underreported, with only around $15 \%$ of those that were victim to a sexual offence choosing to report it to the Police (Ministry of Justice, 2013). Consequently, the SCAS database may only represent a fraction of all committed stranger rape offences, with a lack of understanding as to how detected and undetected stranger rapists may differ in their crime scene behaviours.

Another limitation is the coding of nationality. A UK stranger rapist may include those born and raised outside UK, but naturalised as a UK national. In addition to this, a significant limitation to this research concerns the sample of Non-UK offenders, as their nationality had been recorded as 'Non-UK' without acknowledging the fact that they may have lived in the UK for decades. Consequently, some Non-UK offenders may have lived in the UK for most of their lives, potentially making their cultural beliefs and behaviours (both generally and offence-specific) to become more aligned with those shared by the UK sample. Exploring the potential within-sample 
differences of the Non-UK stranger rapists is important, to control for any differences that may be explained by the time spent in the UK and may indicate changes in behaviour over time. Furthering this, due to the relative small sample size, all NonUK stranger rapists were grouped together and compared to a UK group, thus creating a 'UK-centric' approach with a lack of understanding as to how other nations may differ from each other, not just from the UK.

\section{Conclusion}

Results of this study indicated that on the whole UK and Non-UK stranger rapists display similar behaviours, but there were some distinct behaviours within stranger rape crime scenes, particularly the use of firearms. Considering that BIA's use crime scene behaviours to predict the previous criminal history of stranger rapists (Almond et al., 2018), this study may be the first step for BIAs to utilise in identifying whether the offender is likely to be a UK or non-UK national.

This information may help direct policing and investigative resources to alternative lines of enquiry, away from using criminal histories, in attempt to identify and detect these serious offenders. Despite its limitations, this study represents the first research of its kind to examine the phenomena of stranger rape, within the context of different nationalities.. 


\section{References}

Aitken, C., Connolly, T., Gammerman, A., Zhang, G., \& Oldfield, R. (1995).

Predicting an Offender's Characteristics: An evaluation of statistical modelling. London: Home Office Report, Police Research Group, Special Interest Series 1995: Paper 4.

Alison, L., Goodwill, A., Almond, L. Van den Heuvel, C. \& Winter, J. (2010).

Pragmatic solutions to offender profiling and behavioural investigative advice. Legal and Criminological Psychology, 15, 115-132.

Alison, L., McLean, C., \& Almond, L. (2007). Profiling Suspects. In T. Newburn, T. Williamson, \& A. Wright (Eds.), Handbook of criminal investigation (pp. 493516). Devon, Cullumpton: Willan Publishers.

Almond, L., McManus, M., Bal, A., O’Brien, F. Rainbow, L. \& Webb, M. (2018). Assisting the investigation of stranger rapes: Predicting the criminal record of UK stranger rapists from their crime scene behaviours. . Journal of Interpersonal Violence https://doi.org/10.1177/0886260518756118

Almond, L., McManus, M. A., Giles, S., \& Houston, E. (2015). Female Sex Offenders: An Analysis of Crime Scene Behaviors. Journal of Interpersonal Violence, 32, 3839-3860.

Banks, J. (2011). Foreign National Prisoners in the UK: Explanations and Implications. The Howard Journal, 50(2), 184-198.

Canter, D., Bennell, C., Alison, L. \& Reddy. (2003). Differntiating sexual offenders: a behaviorally based thematic classification of stranger rapes. Behavioral Sciences and the Law, 21, 157-174.

Canter, D, V. (2011). Resolving the Offender Profiling Equations and the Emergence of an Investigative Psychology. Current Directions in Psychological Science, 20(1), 5-10. 
Canter, D. (1994). Criminal Shadows: Inside the mind of the serial killer. Harper Collins.

Chen, H., Cohen, P., \& Chen, S. (2010). How Big is a Big Odds Ratio? Interpreting the Magnitudes of Odds Ratios in Epidemiological Studies. Communications in Statistics - Simulation and Computation, 39, 860-864.

Corovic, J. (2013). Offender Profiling in Cases of Swedish Stranger Rape (Published Doctoral Dissertation), Stockholm University: Stockholm, Sweden.

Corovic, J., Christianson, S. A., \& Bergman, L. R. (2012). From crime scene actions in stranger rape to prediction of rapist type: single-victim or serial rapist? Behavioural Sciences and the Law, 30(6), 764-781.

Davies, A., Wittebrood, K., \& Jackson, J. L. (1997). Predicting the Criminal Antecedents of a Stranger Rapist from his offence Behaviour. Science \& Justice, 37(3), 161-170.

Dempsey, G. A. N. (2016). Briefing Paper: Prison Population Statistics. House of Commons Library. Retrieved from www.parliament.uk/commons-library |intranet.parliament.uk/commons-library

Goodwill, A. M., Alison, L. J., \& Beech, A. R. (2009). What works in Offender Profiling? A Comparison of Typological, Thematic, and Multivariate Models. Behavioural Sciences and the Law, 27, 507-529.

Hakkanen, H., Lindlof, P., \& Santtila, P. (2004). Crime Scene Actions and Offender Characteristics in a Sample of Finnish Stranger Rapes. Journal of Investigative Psychology and Offender Profiling, 1, 17-32.

Howell, A. J., Dopko, R. L., Turowski, J. B., \& Buro, K. (2011). The Disposition to Apologize. Personality and Individual Differences, 51, 509-514. 
Lundrigan, S. \& Müller-Johnson, K. (2013) Male Stranger Rape: A Behavioural Model of Victim-Offender Interaction. Criminal Justice and Behavior, 40(7), 763-783.

McCrae, R. R., \& Terracciano, A. (2005). Personality Profiles of Cultures: Aggregate Personality Traits. Journal of Personality and Social Psychology, 89(3), 407425.

Ministry of Justice, 2010a. Offender management caseload statistics 2009. London: HMSO. Retrieved from: https://www.gov.uk/government/uploads/system/uploads/attachment_data/file/ 218065/omcs-2009-complete-210710a.pdf

Ministry of Justice. (2013). An Overview of Sexual Offending in England and Wales. London: HMSO. Retrieved from: http://webarchive.nationalarchives.gov.uk/20160106113426/http://www.ons.go v.uk/ons/rel/crime-stats/an-overview-of-sexual-offending-in-england--wales/december-2012/index.html

Ministry of Justice. (2017). Foreign National Prisoners. London: HMSO. Retrieved from: https://www.justice.gov.uk/offenders/types-of-offender/foreign

Mokros, A., \& Alison, L. J. (2002). Is offender profiling possible? Testing the Predicted homology of crime scene actions and background characteristics in a sample of rapists. Legal and Criminological Psychology, 7(1), 25-43.

National Crime Agency (2015). National Strategic Assessment of Serious and Organised Crime 2015.

Office for National Statistics. (2015). Crime Survey for England and Wales: Chapter 4: Violent Crime and Sexual Offences - Intimate Personal Violence and Serious Sexual Assault. Retrieved from: 
http://webarchive.nationalarchives.gov.uk/20160105160709/http://www.ons.g ov.uk/ons/dcp171776_394500.pdf [11/3/17]

Petherick, W., \& Ferguson, C. (2012). Criminal profiling: Behavioural consistency, the homology assumption and case linkage. In F. Almeida \& M. Paulino (Eds.), Profiling, Vitimologia e Ciências Forenses: Perspetivas Atuais (pp. 227- 243). Lisbon, Portugal: Pactor.

Scott, D., Lambie, I., Henwood, D., \& Lamb, R. (2006). Profiling Stranger Rapists: Linking Offence Behaviour to Previous Criminal Histories Using a Regression Model. Journal of Sexual Aggression, 12(3), 265-275. 
Table 1. Offence variables

\begin{tabular}{|c|c|c|c|}
\hline Offence Behaviour Variables & $\begin{array}{r}\% \text { Non-UK } \\
N=217\end{array}$ & $\begin{array}{c}\text { \% UK sample } \\
\mathrm{N}=434\end{array}$ & $\begin{array}{r}\% \text { All } \\
\mathrm{N}=651\end{array}$ \\
\hline Confidence Approach* & 56.2 & 46.3 & 49.6 \\
\hline Outdoors & 70.5 & 66.1 & 67.6 \\
\hline Darkness* & 89.4 & 81.6 & 84.2 \\
\hline Offender Kisses Victim* & 56.2 & 47.5 & 50.4 \\
\hline Self-Disclosure & 43.3 & 46.3 & 45.3 \\
\hline Victim Performs Sex Acts* & 40.6 & 54.4 & 49.8 \\
\hline Request Sex Acts* & 37.3 & 45.6 & 42.9 \\
\hline Curiosity & 35.0 & 36.6 & 36.1 \\
\hline Reassurance & 24.9 & 27.0 & 26.3 \\
\hline Compliments Victim & 17.5 & 18.9 & 18.4 \\
\hline Victim Enjoyment Reference & 15.7 & 18.4 & 17.5 \\
\hline Implies Prolonged Relationship & 13.8 & 9.2 & 10.8 \\
\hline Offender Apologises* & 9.7 & 16.1 & 14 \\
\hline Requests Victim Participation & 9.2 & 9.9 & 9.7 \\
\hline Implies Victim Knowledge & 6.9 & 9.4 & 8.6 \\
\hline Reference to Police & 10.1 & 9.9 & 10 \\
\hline Condom Used & 7.8 & 7.6 & 7.7 \\
\hline Fingerprint Precaution & 4.6 & 4.1 & 4.3 \\
\hline Destroy Forensics* & 4.6 & 9.7 & 8 \\
\hline Gagged Victim & 4.1 & 3.7 & 3.8 \\
\hline No Speech & 2.3 & 1.8 & 2 \\
\hline Blindfold Victim & 1.8 & 1.2 & 1.4 \\
\hline Sighting Precaution & 1.4 & 2.8 & 2.3 \\
\hline No Precautions & 29.5 & 33.6 & 32.3 \\
\hline Block Entry/Exit ${ }^{*}$ & 18.4 & 11.8 & 14 \\
\hline Threatens No Report & 18.0 & 22.4 & 20.9 \\
\hline Verbalise Safe Departure & 9.2 & 11.1 & 10.4 \\
\hline Disable Victim's Phone & 1.4 & 2.5 & 2.2 \\
\hline Property Stolen & 34.6 & 32.3 & 33 \\
\hline Abduction & 16.1 & 14.5 & 15.1 \\
\hline Burglary & 10.6 & 12.4 & 11.8 \\
\hline Victim's Clothing Removed & 84.3 & 82.7 & 83.3 \\
\hline Offender Disrobes Self & 79.7 & 79.5 & 79.6 \\
\hline Offender Disrobes Victim & 69.6 & 63.4 & 65.4 \\
\hline Clothing Ripped/Torn & 15.7 & 15.7 & 15.7 \\
\hline Both Disrobe Victim & 7.8 & 11.1 & 10 \\
\hline Victim Disrobes Self & 6.9 & 8.3 & 7.8 \\
\hline Both Disrobe Offender & 0.8 & 1.2 & 0.8 \\
\hline Victim Disrobes Offender & 0.5 & 0.5 & 0.5 \\
\hline Verbal Threats & 47.0 & 49.5 & 48.7 \\
\hline Weapon Use & 12.4 & 17.5 & 15.8 \\
\hline Weapon - Stabbing & 16.1 & 21.9 & 20 \\
\hline Weapon Brought & 15.2 & 16.6 & 16.1 \\
\hline Weapon Found & 6.5 & 4.4 & 5.1 \\
\hline Binds Victim & 3.4 & 3.0 & 3.4 \\
\hline Weapon - Firearm ${ }^{* * *}$ & 2.8 & 1.2 & 2.8 \\
\hline Weapon - Multiple & 2.3 & 3.5 & 3.1 \\
\hline Weapon - Bludgeoning & 1.8 & 1.4 & 1.8 \\
\hline
\end{tabular}


Weapon - Other

Weapon - Ligature

Weapon Taken from Victim

Physical Violence

Multiple Violent Acts

Violence: Minimal*

Violence: Moderate

Abusive Language

Violence: Severe

Verbal Cruelty

Vaginal Penetration: Penile

Vaginal Penetration: Digits*

Anal Penetration: Penile

Vaginal Penetration From Rear

Oral by Offender

Offender Masturbates Self

Anal Penetration - Digits

Vaginal Penetration: Unknown

Anal Penetration From Front

Vaginal Penetration: Foreign

Object

Anal Penetration: Foreign

Object

Anal Penetration: Unknown

$\begin{array}{rrr}1.4 & 2.5 & 2.2 \\ 0 & 0.5 & 0.3 \\ 0 & 0.7 & 0.5\end{array}$

$\begin{array}{lll}53.9 & 51.8 & 52.5\end{array}$

$\begin{array}{lll}34.1 & 32.0 & 32.7\end{array}$

$\begin{array}{lll}26.3 & 18.7 & 21.2\end{array}$

$\begin{array}{lll}15.2 & 17.7 & 16.9\end{array}$

$\begin{array}{lll}12.4 & 17.3 & 15.7\end{array}$

$\begin{array}{lll}4.6 & 4.6 & 4.6\end{array}$

$\begin{array}{lll}3.2 & 6.0 & 5.1\end{array}$

$\begin{array}{lll}73.7 & 69.8 & 71.1\end{array}$

$\begin{array}{lll}25.3 & 35.9 & 32.4\end{array}$

$\begin{array}{lll}24.0 & 17.5 & 19.7\end{array}$

$\begin{array}{lll}23.0 & 20.7 & 21.5\end{array}$

$\begin{array}{lll}12.0 & 10.8 & 11.2\end{array}$

$\begin{array}{lll}10.6 & 12.9 & 12.1\end{array}$

$\begin{array}{lll}3.7 & 7.6 & 6.3\end{array}$

$\begin{array}{lll}2.3 & 3.7 & 3.2\end{array}$

$\begin{array}{lll}0.9 & 1.4 & 1.2\end{array}$

$\begin{array}{lll}0 & 1.8 & 1.2\end{array}$

$\begin{array}{lll}0 & 0.9 & 0.6\end{array}$

$\begin{array}{lll}0 & 1.4 & 0.9\end{array}$

${ }^{*} p<.05^{* * *} p<.0007$ 
Table 2. Odds ratios displaying the significant relationship between offender nationality and offence behaviours

\begin{tabular}{lcc}
\hline Offence Behaviour & $\begin{array}{c}\text { Non-UK Nationality } \\
\text { OR }(95 \% \text { Cl })\end{array}$ & $\begin{array}{c}\text { UK Nationality } \\
\text { OR (95\%Cl) }\end{array}$ \\
\hline Confidence Approach & $1.49(1.07-2.07)$ & \\
Darkness & $1.91^{\mathrm{M}}(1.16-3.13)$ & \\
Offender Kisses Victim & $1.42(1.02-1.97)$ & $1.75^{\mathrm{M}}(1.26-2.43)$ \\
Victim Performs Sex Acts & & $1.41(1.01-1.97)$ \\
Requests Sex Acts & $1.79^{\mathrm{M}}(1.07-3.01)$ \\
Apologises & & $2.22^{\mathrm{M}}(1.09-4.51)$ \\
Destroys Forensics & $1.70^{\mathrm{M}}(1.08-2.66)$ & \\
Block Entry/Exit & $5.47^{\mathrm{L}}(1.92-15.54)$ & \\
Weapon Type - Firearm * & $1.55^{\mathrm{M}}(1.05-2.29)$ & \\
Minimal Damage & & $1.65^{\mathrm{M}}(1.15-2.38)$ \\
Vaginal Penetration: Hands/Fist/Digital & & \\
\hline
\end{tabular}

